\title{
A RECUSA DO MARXISMO VULGAR OU A CRÍTICA DO "PROGRESSO": QUE AS COISAS CONTINUEM ASSIM, EIS A CATÁSTROFE
}

\author{
Marta Maria Aragão Maciel ${ }^{1}$
}

\begin{abstract}
Resumo
Tendo vivido quase um século, Ernst Bloch viveu em sua quase totalidade o século XX. Em tal período, toda uma tradição do pensamento social crítico questionou o ideal de progresso dominante entre os séculos XVIII e XIX, ou seja, a época de expansão da burguesia em direção ao planeta inteiro. O escritor de Ludwigshafen, assim como outros pensadores da tradição alemã como Adorno e Benjamin, refletiu a relação entre progresso e catástrofe, rompendo com a ideia de um curso inevitável na história tendendo ao melhor. Na linha dessa reflexão, pretendemos abordar a filosofia de Ernst Bloch, particularmente em O princípio esperança [Das Prinzip Hoffnung], no interior da necessária crítica ao marxismo vulgar da social-democracia alemã da Segunda Internacional. No entender do filósofo, em sua visão determinista e antidialética da história, a social-democracia teria aderido ao ideal burguês de progresso fundado na simbiose entre progresso técnico e progresso social. Em sua opus magna, o pensador enfatiza que tal visão da história, pautada no otimismo de um progresso automático, estaria na contramão do "marxismo crítico".
\end{abstract}

Palavras-chave: Marxismo. Dialética. Crítica do presente. Herança cultural.

\section{THE REFUSAL OF VULGAR MARXISM OR THE CRITICISM OF "PROGRESS": MAY THE THINGS REMAIN SO, THIS IS A DISASTER}

\begin{abstract}
Having lived almost a century, Ernst Bloch lived the 20th century almost entirely. During this period, a tradition of social critical thinking questioned the dominant ideal of progress in the 18th and 19th centuries, that is, the period of expansion of the bourgeoisie toward the entire planet. Like other thinkers in the German tradition such as Adorno and Benjamin, Ludwigshafen's writer reflects on the relationship progress and disaster by breaking with the idea of an inevitable course of history, which tends to the best. And in relation to this thought, we intend to approach Bloch's philosophy, especially The principle of Hope [Das Prinzip Hoffnung] within the necessary criticism to the vulgar Marxism of German Social Democracy of the Second International. According to Bloch, in its deterministic and anti-dialectical view of history, social democracy would have joined the bourgeoise of progress based on the symbiosis between technical progress and social progress. In his magnum opus, the thinker emphasizes that such a view of history based on the optimism of an automatic progress would be against the "critical Marxism".
\end{abstract}

Keywords: Marxism; Dialectic; Criticism of the present; Cultural heritage.

1 Graduada em Filosofia pela Universidade Estadual do Ceará (UECE). Mestre em Filosofia pela Universidade Federal da Paraíba (UFPB). Doutora em Filosofia pelo Programa Integrado de Pós-graduação em Filosofia (UFPB/UFPE/UFRN). Membro do GEFICS (Grupo de Pesquisa em Filosofia e Crítica Social da UFPB). Email: maciel_mart@yahoo.com.br. 


\title{
A crítica ao marxismo vulgar e a recusa ao "otimismo banal e automático do progresso"
}

\author{
A Bastilha deve ser tomada, e foi tomada, sendo um bom signo para o futuro \\ que isto tenha ocorrido, e que seja ainda possível (BLOCH, 2016b, p. 173).
}

Em ensaio dedicado a Ernst Bloch, fazendo um diagnóstico do século $\mathrm{XX}$, o filósofo Jürgen Habermas constata que, "na conjuntura atual, a cotação da utopia está baixa. (...) O mundo ocidental se entrincheira contra o futuro" (Habermas, 1993, p. 154). Numa época marcada por conflitos de repercussão mundial nos quais se fez uso de armas bélicas com poder de destruição em massa, se entrava em crise o ideal moderno de um progresso rumando a etapas de desenvolvimento cada vez mais superiores. Inúmeros discursos pessimistas marcam tal época. É nesse quadro histórico que Ernst Bloch tenta contribuir no âmbito de um pensamento social-crítico, retomando como atual para a filosofia política o conceito de utopia. Com efeito, a necessária recusa do ideal de progresso que predominou na modernidade não deveria coincidir com a recusa de uma razão emancipatória capaz de realizar a crítica do presente.

Na síntese única de influências e confluências que formam seu pensamento, Bloch é conhecido como o filósofo marxista da utopia. Ora, utopia e marxismo foram geralmente tidos como compondo um casamento antinatural. Em O Princípio Esperança, em particular, e na obra de Ernst Bloch em sua totalidade, se fossemos elencar um único conceito como central, certamente este seria o de utopia. Trata-se de conceito capaz de aglutinar todas as grandes questões que compõem a produção teórica do filósofo alemão, bem como a tornam compreensível no interior de problemas para cuja solução se quer contribuir. Assim, antes de mais nada, ao nos reportarmos à obra $O$ Princípio Esperança, convém ressaltar, conforme entende Arno Münster, que trata-se de "um dos textos mais importantes no interior da discussão marxista de nossa época" (MÜNSTER, 1997, p. 15).

O século XX que conheceu experiências inéditas da violência produzida em massa em fenômenos limite como os campos de concentração nazistas e a barbárie produzida pelo stalinismo, representou um espelho refletor que deu origem a inúmeras obras literárias e filosóficas distópicas que anunciaram/anunciam o fim e o fracasso de todo discurso emancipatório, lançando sobre o real um pessimismo, por assim dizer, "ontologizado", produzindo "um tipo de realismo que parece existir como tal apenas na resignação" (BLOCH, 2006b, p. 452). Em particular depois de experiências como o fim da ex-União Soviética e a queda do muro de Berlim, inúmeros teóricos anunciaram a superação do marxismo e a 
impossibilidade de sustentação do ideal de uma sociedade pós-capitalista. Em 1955, Raymond Aron sustentou que seria correto anunciar o fim da era das ideologias, devendo entender-se por isso que os conceitos de utopia e revolução deveriam ser tomados como completamente superados na história. Outro importante exemplar das formulações que afirmaram a inconsistência de qualquer pensamento crítico-revolucionário está em Fukuyama. Em O Fim da história e o último homem, este anuncia o fim da utopia:

Hoje, em compensação, temos dificuldade para imaginar um mundo radicalmente melhor que o nosso, ou um futuro que não seja essencialmente democrático e capitalista. [...] Também podemos imaginar mundos futuros consideravelmente piores que o que hoje conhecemos. [...] Mas não podemos visualizar um mundo que seja essencialmente diferente do atual, e ao mesmo tempo melhor (FUKUYAMA apud JACOBY, 2001, p. 25).

Na erudita e enciclopédica obra $O$ Princípio Esperança, escrita no exílio durante os anos do avanço nazista na Europa, se desenha precisamente a tentativa de refletir a atualidade das ideias de utopia e futuro. Nos anos de reclusão nos Estados Unidos, foi marcante para Bloch o pessimismo em que, em sua visão, teriam culminado Adorno e Horkheimer, dois dos mais importantes pensadores do período ${ }^{2}$. Desde já, é válido enfatizar que o autor pretende dar respostas a problemas concretos de seu tempo. E já nesse viés, na preocupação em atualizar o conceito de utopia como categoria filosófica central, é fundamental "reivindicar a figura de Ernst Bloch como pensador marxista" (IVARS apud ZECCHI, 1978, p. 07). É nessa direção que, em entrevista a Jean-Michel Palmier no ano de 1970, diz a seu interlocutor:

Sempre escutamos falar de uma coisa para depreciá-la: "Isto é somente uma utopia". $\mathrm{Na}$ atualidade, a utopia é uma importante categoria filosófica e marxista. [...] Quando eu falei de uma utopia concreta, as pessoas riram. Isso lhes parecia absurdo, tanto quanto quando falamos de um círculo quadrado. [...] Em meu livro O Espírito da utopia, eu quis mostrar que a palavra utopia, longe de ser um termo maldito, é a categoria filosófica do nosso século. A utopia está longe de se limitar à esfera social. [...] Por outro lado, não é um conceito novo: ela teve um papel determinante na Revolução Francesa, ao longo da Comuna de Paris e, hoje, em toda juventude que luta para construir outro mundo e mudar a vida. [...] Historicamente, a utopia tem sido uma força social que joga um papel (BLOCH, 1970, p. 82-84).

Uma questão crucial que se coloca desde já é: de qual marxismo Bloch se tornou herdeiro? A resposta a tal questão pode ser vislumbrada na crítica que, de O Espírito da utopia ao texto de $O$ Princípio esperança, o pensador realiza, em particular, ao marxismo vulgar da

2 Sobre a recepção de Bloch frente à produção teórica de Adorno e Horkheimer durante e após os anos do exílio americano, conferir a entrevista do filósofo concedida a Jean-Michel Palmier no ano de 1976. Nesta entrevista, ele diz a seu interlocutor: "Eu nunca aceitei seu pessimismo" (Cf. BLOCH, 2016a, p. 181).

\begin{tabular}{|l|l|l|l|l|}
\hline Rovista Qialectus & Ano 10 & n. 21 & Janeiro - Abril 2021 & p. 116-135
\end{tabular}


social-democracia alemã ${ }^{3}$. Se referindo a esta, e como se estivesse falando da revolução traída pela mesma na Alemanha entre os anos 1918-1923, o pensador escreve que para "a socialdemocracia alemã [...] a revolução ocorre de mansinho e se chama apenas continuidade. [...] Dessa maneira, a ação é constantemente adiada para o tempo dos filhos, e dos filhos dos filhos" (BLOCH, 2006b, p. 22-23).

\section{Juntamente com György Lukács ${ }^{4}$ e Karl Korsch, Ernst Bloch ficou conhecido como}

um dos três grandes filósofos "marxistas hegelianos", de acordo com formulação de Habermas.

3 A aproximação de Ernst Bloch do marxismo remonta ao intervalo de tempo que permeia a Primeira Guerra e a Revolução Russa. Em seus livros mais importantes, incluindo sua obra máxima - O Princípio esperança -, o marxismo que Bloch acusa de "tacanho" e mesmo de "antimarxismo" (Cf. BLOCH, 2005, p. 196) diz respeito à social-democracia da Segunda Internacional. Nas linhas do texto de O Princípio esperança, Bloch apresenta certa "ingenuidade", ou um olhar pouco crítico, frente ao marxismo soviético. Neste, podemos ler, por exemplo, o autor explicitar que "a União soviética não conhece mais uma questão da mulher, porque solucionou a questão operária. Onde acabam senhores e servos desaparece também o extrato inferior: a mulher" (Cf. BLOCH, 2006a, p. 150). Certamente poderíamos pensar que o comentário de Bloch não se distancia muito das posições ideológicas da imprensa oficial do regime stalinista. Entretanto, se do ponto de vista político $O$ Princípio Esperança ainda não havia rompido com o stalinismo, na perspectiva teórica não coincidiu em momento algum. Quando do fim da Segunda Guerra, após todo o horror produzido nos campos de concentração nazistas, o autor judeu retorna à Alemanha Oriental, sob a justificativa de contribuir para a construção do socialismo, contra o perigo que representou o capitalismo no século XX. Durante um tempo, teve livre atuação na Universidade de Leipzig, onde dirigiu a Deutsche Zeitschrift für Philosophie. Não tardou, todavia, para que Bloch e seus colaboradores assumissem a postura de denúncia política da burocracia stalinista. Em 1956, acusando a burocracia estatal e partidária de se afastar cada vez mais dos interesses coletivos, Bloch escreve: "O povo trabalhador não deve chegar a saber que está bem governado, senão que ele mesmo deve governar" (BLOCH apud ZECCHI, 1978, p. 49). Ernst Bloch foi afastado de suas atividades, e passou a viver constantemente sob vigilância policial. Em 1961, em razão da construção do muro de Berlim, decidiu viver na Alemanha Ocidental. Morreu em 1977 sem jamais ter voltado à Alemanha Oriental, mas também sem jamais ter abandonado a "esperança" em grandes mudanças históricas. Quanto à relação do filósofo com o marxismo stalinista, convém considerar o seguinte comentário de Pierre Furter, ao esclarecer que "Bloch, ao aceitar ser cidadão da DDR, nunca admitiu que a sua escolha incluísse uma submissão intelectual à censura da ortodoxia partidária. [...] Portanto, não deu a mínima importância às advertências, às censuras, às pressões diretas ou indiretas dos ortodoxos do PC. Longe de ser um 'filósofo de parada' [...], Bloch faz de sua cátedra uma fonte de perpétua inquietação [...]. Torna-se, por consequência, a besta negra dos filósofos oficiais" (Cf. FURTER, 1974, p. 25). Sobre sua posição frente ao socialismo soviético, é esclarecedora a resposta de Bloch em 1976, quando perguntado por Jean-Michel Palmier se seus escritos pertenceriam à tradição marxista: "Sim, mas qual marxismo? Soviético? Certamente não. Não há mais hoje um marxismo único, assim como não existe uma forma única de socialismo. É evidente que estou em desacordo com as posições do marxismo soviético" (BLOCH, 2016a, p. 181).

4 Bloch havia conhecido Lukács em Berlim na casa de Georg Simmel, de quem era muito próximo. Logo travariam uma amizade e uma afinidade intelectual de extrema proximidade, de tal modo que Bloch, em entrevista a Löwy em março de 1974, fala acerca dessa amizade nos seguintes termos: "rapidamente descobrimos que tínhamos a mesma opinião sobre todas as coisas; uma identidade tão grande sobre pontos de vista que fundamos uma "reserva nacional" (Naturschuptzpark) de nossas diferenças, para que não disséssemos sempre as mesmas coisas. [...] Quando nos separávamos por alguns meses, e nos encontrávamos depois, descobríamos que ambos havíamos trabalhado exatamente no mesmo sentido; eu poderia continuar de onde ele havia parado e vice-versa; éramos como vasos comunicantes" (LÖWY, 1998, p. 296-297). Se, por meio dessa amizade, Bloch afirma ter chegado a Mestre Eckart via Lukács, foi via Bloch a "descoberta” de Hegel que culminaria na elaboração de História e consciência de classe, de Lukács. Conforme explicitou Bloch, "em História e consciência de classe há partes e pensamentos que são a expressão de uma atitude comum e que na verdade vem de mim; da mesma forma, em Geist der Utopie há partes e conteúdos originais de conversas com Lukács" (LÖWY, 1998, p. 298). O filósofo alemão afirma que em 1921 a "reserva nacional" já era desnecessária. As divergências artificialmente criadas passaram a ser divergências reais quando, na visão de

\begin{tabular}{|c|c|c|c|c|}
\hline Revista Dialectus & Ano 10 & n. 21 & Janeiro - Abril 2021 & p. $116-135$ \\
\hline
\end{tabular}


Esse fato é, aliás, elemento crucial. Retomar o conceito de utopia como central para a filosofia política contemporânea e vinculá-la ao marxismo significava, no interior da obra do autor em questão, resgatar a dialética sujeito-objeto, a ideia do homem como sujeito histórico. Em suma, tratava-se de retomar o marxismo como o que poderíamos chamar de uma teoria crítica ${ }^{5}$, conforme definição dada por Horkheimer: “A teoria crítica da sociedade, ao contrário [da teoria tradicional], tem como objeto os homens como produtores de todas as suas formas históricas de vida. [...] O que é dado não depende apenas da natureza, mas também do poder do homem sobre ela" (HORKHEIMER, 1975, p. 169). É nessa mesma direção que Ernst Bloch caracteriza o marxismo como uma filosofia da revolução, expressão provavelmente tomada de Karl Korsch, também crítico radical do marxismo vulgar 6 .

Bloch, a aproximação de Lukács com o partido e com Moscou distanciaram suas perspectivas. Dentre os elementos que marcam essa fase, está a negação, por Lukács, do livro História e consciência de classe, obra caracterizada pela crítica ao marxismo vulgar e pelo insistente debate sobre o marxismo como um pensamento dialético marcado pela influência de Hegel, influência negada pelo marxismo dominante, o mesmo que exigia o direito à "ortodoxia".

5 Aqui, evidentemente, tomamos a ideia de teoria presente no movimento da chamada Escola de Frankfurt. Tal ideia de teoria é oriunda, todavia, do próprio marxismo, tal como Bloch debate amplamente em sua discussão sobre as Teses sobre Feuerbach na obra O Princípio esperança. No contexto de uma teoria crítica é claramente refletido - e é justamente isso que pretendemos extrair aqui - que a ideia de conhecimento não existe desvinculada das relações histórico-sociais, de modo que uma orientação meramente hermenêutica da teoria não serviria para fundamentar uma teoria social crítica. Em outras palavras, a atividade teórica não deve ser tomada de um modo isolado, separado da atividade prática, de modo que ao falar em teoria crítica, dialética, falamos em uma teoria que se recusa a simplesmente descrever o real existente, mas ocupa-se também com sua transformação enquanto realidade humana e histórica.

6 Em O Princípio esperança, Bloch aponta ser o marxismo "não falsificado" uma filosofia da revolução. Tal expressão parece ter sido tomada do livro Marxismo e filosofia, de Karl Korsch, escrito em 1923, mesmo ano de publicação de História e consciência de classe, de cujas ideias o próprio Korsch apontou uma extrema proximidade das ideias expostas em seu livro. Neste, Karl Korsch se defronta ante a necessidade de recusar teoricamente - junto às consequências de ordem prática - o marxismo vulgar e o modelo de ciência que predominou, em particular, no marxismo da Segunda Internacional. Esse modelo pode ser percebido na frase de Rudolf Hilferding, um dos maiores representantes do marxismo dito "ortodoxo": "Identificar pura e simplesmente marxismo com socialismo é [...] uma concepção falsa, ainda que muito difundida intra et extra muros. Porque, considerado logicamente apenas como sistema científico, abstraindo, pois, das suas consequências históricas, o marxismo não é senão uma teoria das leis da evolução da sociedade, que a concepção marxista da história formula na sua generalidade, enquanto a economia marxista as aplica à época da produção industrial. [...] Mas o reconhecimento da justeza do marxismo, que inclui o reconhecimento da necessidade do socialismo, não é de modo algum uma formulação de juízo de valor nem tampouco uma indicação de comportamento prático a adotar. Porque uma coisa é reconhecer uma necessidade e outra pôr-se ao serviço dessa necessidade" (HILFERDING apud KORSCH, 1966, p. 95). Em outros termos, no interior do processo de vulgarização do marxismo se encontrou o retorno ao dualismo da filosofia e ciência burguesa, separando teoria e prática, conhecimento-ação, sujeito-objeto, ciência e socialismo, dialética e materialismo. Assim, ainda no dizer de Karl Korsch a propósito do marxismo vulgar, "sobre esta origem histórica do marxismo atual repousa a separação entre teoria e prática que lhe é inata desde o princípio. [...] A separação entre teoria e prática, existente desde o início [do processo de vulgarização] [...], aguçou-se cada vez mais" (KORSCH, 1966, p. 118-119). Em Bloch, como em Korsch, a retomada de Hegel e da influência que este pensador teria exercido para o marxismo se vincula à recusa do marxismo vulgar - em especial a socialdemocracia, com quem se defrontou diretamente em seus escritos - e de seu modelo de ciência: uma ciência pura, desvinculada da realidade, deixando de lado a filosofia (em particular Hegel, e o jovem Marx, influenciado por àquele). Poderíamos vincular a crítica de Bloch ao marxismo vulgar justamente àquele elemento que corresponde ao grande limite do materialismo sensualista de Feuerbach e que o limitou a um

\begin{tabular}{|l|l|l|l|l|}
\hline Revista Dialectus & Ano 10 & n. 21 & Janeiro - Abril 2021 & p. $116-135$ \\
\hline
\end{tabular}


Em O Princípio esperança, podemos apontar Bloch no interior de uma tradição crítica do ideal de progresso burguês moderno, tradição essa na qual podemos incluir Theodor Adorno e Walter Benjamin, pensadores que foram seus interlocutores. O ideal burguês de progresso representou uma concepção do tempo histórico que expressou, como escreveu o historiador Reinhart Koselleck, um "giro para o futuro" (KOSELLECK, 2006, p. 278) e para o novo. No período de tempo em que a burguesia, partindo do contexto europeu, reivindicou a posse do mundo inteiro, surgiu uma concepção do tempo histórico que abraçou de modo ilimitado a ideia de progresso. Se entendia, nessa visão do mundo, que a história seria necessariamente "conduzida em direção a um futuro melhor" (KOSELLECK, 1999, p. 10).

Foi precisamente a barbárie experienciada no século XX que questionou o progresso presente nas "promessas" do ideal burguês. Tal como expressou a teoria crítica, experiências como o nazismo, o stalinismo e duas grandes guerras a ameaçar o planeta mostraram a experiência da desrazão e a concretização da catástrofe que pode prevalecer no curso da história. Também Bloch, ao enfatizar o caráter ameaçador presente na técnica burguesa fundada na não aliança entre o homem e a natureza, enfatiza que "a catástrofe técnica subentende cada vez mais também o nada ameaçador, como não mediação definitiva" (BLOCH, 2006a, p. 250).

Em outros termos, se afirma a existência de uma relação entre progresso e catástrofe, relação refletida no contexto cultural alemão também por interlocutores de Ernst Bloch, como Walter Benjamin e Theodor Adorno. Esse último, junto a Max Horkheimer, na Dialética do esclarecimento (1947) - obra escrita no mesmo contexto político e geográfico do exílio americano onde Bloch escreveu sua obra enciclopédica -, desmistificam a ideia de um progresso linear como sinônimo de emancipação e liberdade humana que, da Antiguidade, atinge a sociedade industrial. Escrevem: "a humanidade, em vez de entrar em um estado

materialismo mecânico: "Feuerbach não conseguiu encontrar o caminho até a realidade; ele jogou fora justamente o mais importante em Hegel, o método dialético-histórico" (BLOCH, 2005, p. 250). Assim, o autor reafirma, junto à Tese 11 de Marx, que não há oposição entre conhecer e transformar. Aliás, não somente teoria e prática não se desvinculam, mas, no caso do marxismo, trata-se de uma teoria que é expressão direta das lutas do proletariado. Nessa direção, Bloch escreve que a incumbência do proletariado foi "o estímulo que levou a nova filosofia de imediato às barricadas" (BLOCH, 2005, p. 278). É desta feita que Ernst Bloch recusa, também, a posição que separa o marxismo, entendido como teoria científica, do socialismo, compreendido como prática política: uma perspectiva abstrata da "evolução" social, uma concepção fundada em leis pretensamente objetivas e de um desenvolvimento inevitável, numa atitude não marxista e mesmo préhegeliana (não dialética) do conhecimento. Logo, não por acaso Ernst Bloch denomina o marxismo, enquanto teoria, de filosofia da revolução, no mesmo sentido em que é interpretado como utopia concreta (Cf. BLOCH, 2005, p. 278). Em suma, é no contexto desse debate no interior do marxismo que a obra de Bloch deve ser lida enquanto perspectiva teórica que tenta resgatar o vínculo não somente entre teoria e prática mas, na raiz desta relação, o vínculo entre o real e os sujeitos produtores/autoprodutores.

\begin{tabular}{|l|l|l|l|l|}
\hline Govista Dialectus & Ano 10 & n. 21 & Janeiro - Abril 2021 & p. $116-135$ \\
\hline
\end{tabular}


verdadeiramente humano, está se afundando em uma nova espécie de barbárie" (ADORNO; HORKHEIMER, 1985, p. 11). Com efeito, o processo do esclarecimento, o cada vez maior domínio das forças da natureza pelo homem obtido pelo desenvolvimento técnico - o "progresso" - não os tornou mais livres, mais emancipados. Se o projeto do esclarecimento era opor-se ao destino cego na história humana, esse foi precisamente o seu resultado: os homens se encontram amarrados e dominados por forças que eles próprios criaram e às quais não dominam. Em outros termos, esse progresso aparece como regressão: "a maldição do progresso irrefreável é a irrefreável regressão" (ADORNO; HORKHEIMER, 1985, p. 41). Com alguma proximidade das reflexões de Adorno e Horkheimer, Walter Benjamin, amigo de juventude de quem Bloch chegou a afirmar ter tido uma simbiose filosófica nos anos 1920, refletiu, em vários de seus trabalhos, o caráter nefasto do ideal de progresso que dominou a burguesia em ascensão:

\footnotetext{
No século XIX, quando a burguesia consolidou sua posição de poder, o conceito de progresso foi perdendo cada vez mais as funções que originalmente possuía. (A doutrina da seleção natural teve uma importância decisiva neste processo: com ela fortaleceu-se a opinião de que o progresso se realiza automaticamente) (BENJAMIN, 2007, p. 518-519).
}

O ideal burguês de progresso foi refletido por Bloch em sua identidade direta com o desenvolvimento técnico-científico. O filósofo refletiu, nessa direção, acerca dos riscos presentes na técnica moderna em razão de sua apropriação privada, fundada nos interesses do capital. Por isso, compreende que "a técnica existente até hoje se posiciona na natureza como um exército de ocupação em território inimigo" (BLOCH, 2006a, p. 250). Desta feita, rechaça a identidade que a sociedade burguesa tentou engendrar entre progresso técnico e progresso social, de modo a também identificar uma relação entre progresso e catástrofe nos marcos do capitalismo. Assim, quase que a citar Walter Benjamin, enfatiza que "é possível que aos progressos do 'domínio sobre a natureza' correspondam retrocessos muito grandes da sociedade. [...] [Isto] Representa o fenômeno de uma sociedade violenta” (BLOCH, 2006a, p. 250).

A crítica que o filósofo direciona ao marxismo vulgar sugere que esta tradição caiu numa concepção burguesa e antidialética da história. A recusa do marxismo dominante dá-se, com efeito, no rechaço a uma visão determinista e objetivista da história fundada na concepção de um desenvolvimento e progresso inevitáveis das forças produtivas. Foi precisamente ante a necessidade de combater um marxismo deturpado, positivista e, portanto, antidialético, que 
Ernst Bloch buscou ressaltar, em seu pensamento, o papel das forças subjetivas nas transformações históricas. Por isso,

O marxismo de Bloch [...] é mais bem entendido como crítica da tradição marxista, a qual, em nome da prática revolucionária, degrada, num esquematismo pragmatista, a imaginação revolucionária; tal atitude leva a degenerar o marxismo em um dogma, tomando-se o pensamento de Marx apenas pela metade ao privilegiar um naturalismo cientificista das "leis da história (HUDSON apud VIEIRA, 2010, p. 29-30).

Para Ernst Bloch, o ideal de progresso mecânico e irrefreável significava a aceitação de um destino cego, a aceitação da irracionalidade de um progresso automático que pode aparecer como catástrofe na história humana (Cf. BLOCH, 2005, p. 196). Logo, a recusa do ideal de progresso burguês perpassava, necessariamente, a recusa do marxismo vulgar, ele próprio uma linha teórica que havia se limitado a uma visão positivista do real. A crítica a esse marxismo "cientificista" perpassou, precisamente, o resgate da dialética e de $\mathrm{Hegel}^{7}$, reavaliando o ponto percebido por Marx como o cerne da dialética, ou seja, a do homem trabalhador, ativo, fabricador da história, aquele que "anula o destino na história" (BLOCH, 2005, p. 249). Daí a insistência no sujeito histórico.

Em seu amplo trabalho e, de maneira mais amadurecida, em O Princípio esperança, a crítica de Bloch ao marxismo da social-democracia surge como oposição ao empobrecimento

7 Assim como Korsch, Horkheimer, o Lúkacs de História e consciência de classe, entre outros pensadores de tradição crítica, contra o "economicismo" e o determinismo do marxismo vulgar, Ernst Bloch insistiu na retomada da dialética marxista, influenciada por Hegel, e de seu cerne na relação sujeito-objeto. Aliás, Bloch chegou a escrever uma obra inteira dedicada ao autor de A Fenomenologia do espírito, revelando a relevância dada a Hegel, pensador rechaçado por parte da ortodoxia marxista. Em seu livro dedicado a Hegel, podemos ler Ernst Bloch esclarecer que "no mundo dos grandes pensamentos que avançam e progridem, [...] ficam sempre de pé coisas não liquidadas, não invalidadas; no entanto, estas coisas não invalidadas constituem o mais essencial substrato da herança cultural. Tampouco em Hegel - nele menos que em nenhum outro - esta herança é algo fechado e definitivo: não existe nenhum passado que percorra o nosso passo até o futuro tão repleto de problemas como o de Hegel" (BLOCH, 1963, p. 8). Em Bloch, a utopia está completamente voltada para o front do mundo, na tendência para o novo. Em O Princípio esperança, o autor chega a afirmar que existe uma utopia escondida, em estado embrionário, e que "irrompe em cada estágio do processo hegeliano" (BLOCH, 2005 , p. 140). Esse elemento utópico consiste precisamente na dialética hegeliana que, compreendendo o real como processo, recusa toda concepção contemplativa que compreende o mundo como um amontoado de coisas fixas e estabelecidas de uma vez por todas. Tendo sido Hegel o primeiro pensador a teorizar acerca do papel da práxis humana na gênese da história, podemos entender que o encontro entre o materialista Ernst Bloch e o idealista Hegel se dá precisamente na preocupação com o âmbito da história, espaço no qual a liberdade pode se efetivar. Nessa medida, nas entrelinhas de seu texto sobre Hegel, Ernst Bloch está também a recusar o abandono de Hegel por parte da tradição marxista, a mesma que caiu em um materialismo antes mecânico do que dialético. Assim, ao se reportar à Fenomenologia do espírito, o filósofo marxista da utopia escreve o seguinte: "O que a este filósofo lhe preocupava era, sobretudo, o eu que se abre a caminho do conhecimento e do verdadeiro, que é o real. E a verdade não é nunca o fato em repouso ou estabelecido [...]. A verdade, enquanto realidade, é muito mais o resultado de um processo. Tal processo é o que falta esclarecer e obter. Hegel é um dos nomes mais relevantes para esse objetivo, tanto pela dialética como pela extensão dos seus testemunhos. Quem aspire à verdade tem que adentrar nesta filosofia, mesmo que a verdade não se detenha nela. Hegel não negou o porvir. Nenhum futuro renegará Hegel” (BLOCH, 1963, p. 8).

\begin{tabular}{|l|l|l|l|l|}
\hline Q Rovista Dialectus & Ano 10 & n. 21 & Janeiro - Abril 2021 & p. $116-135$ \\
\hline
\end{tabular}


infligido ao pensamento de Marx pelos teóricos da Segunda Internacional. Sua crítica veemente está enraizada na recusa ao determinismo e objetivismo com que essa tradição compreendia o real. Segundo o filósofo, o ideal de progresso mecânico e irrefreável significava a aceitação de um destino cego pelos homens, a aceitação da irracionalidade de um progresso automático que pode aparecer como catástrofe na história humana (Cf. BLOCH, 2005, p. 196).

Em fins do século XIX, nas mãos da social-democracia alemã da Segunda Internacional, o marxismo havia sido difundido para além do continente europeu. Entretanto, esse processo gradual de difusão do marxismo como programa político no interior do movimento operário havia se dado mediante um cada vez maior processo de deturpação e empobrecimento da teoria. É nessa perspectiva que

O marxismo no seu conjunto [...] se havia empobrecido e se tornara, exatamente, 'marxismo da Segunda Internacional', um marxismo 'vulgar', grosseiramente mecanicista, evolucionista, distanciado da filosofia, mera explicação da necessidade das leis do desenvolvimento histórico, frequentemente traduzido em termos de cientificismo positivista (ANDREUCCI, 1982, p. 22).

É indicativo das consequências práticas que esse empobrecimento teórico engendrou no âmbito da prática política o fato de um jornal como o Neue Zeit, organizado por Karl Kautsky e publicação de maior prestígio da social-democracia alemã, haver sofrido maior "influência das ciências naturais e do darwinismo do que da teoria marxista" (STEINBERG, 1982, p. 249). Tal perspectiva conduziu, de fato, a uma equivocada concepção da história que associava marxismo e darwinismo, concepção essa na qual o conceito fundamental é o de necessidade. Acerca disso, conforme esclarece Iring Fetscher,

Kautsky - e, com ele, quase toda a Segunda Internacional - orienta-se no sentido de afirmações marxianas mal entendidas e acolhidas como obrigatórias, acerca do presumível desenvolvimento do modo de produção capitalista [...]. [Das quais se depreende que] assim como na evolução natural as raças animais se desenvolvem umas a partir das outras, e o homem segue-se aos macacos, do mesmo modo o capitalismo - com uma necessidade igual à fixada pelas leis naturais - será seguido pelo socialismo (FETSCHER, 1982, p. 265)

Na visão de Ernst Bloch, tal concepção comparece como uma espécie de crença no destino à medida que surge como independente dos homens e de sua intervenção na história. $\mathrm{Na}$ obra do filósofo de Ludwigshafen, a crítica a esse ideal de progresso se encontra necessariamente vinculada à problemática da técnica, posto que esse ideal de progresso esteve inexoravelmente associado ao desenvolvimento tecnológico. Escreve Bloch: 
Imagens do progresso meramente tecnológico [...] fizeram com que em todos os tempos o progresso parecesse fácil demais, linear demais, em representações que ainda hoje, isoladas do contexto e omitindo a transformação social, não passam de ilusões falaciosas (BLOCH, 2006a, p. 34).

Se o desenvolvimento técnico comparece como pressuposto para uma sociedade finalmente livre da carência, progresso social e desenvolvimento técnico-científico não se encontram indissoluvelmente ligados. Conforme enfatiza Ernst Bloch, "a fé no progresso amparada tecnologicamente facilitou muitas vezes a ilusão de um êxito e um avanço que nada consegue atrapalhar" (BLOCH, 2006a, p. 250), o que, do ponto de vista político, conduz/conduziu ao conformismo e paralisia. É nessa perspectiva que a crítica ao ideal de progresso automático vincula-se à necessária crítica ao marxismo da Segunda Internacional.

De fato, nos teóricos da social democracia alemã da Segunda Internacional encontramos uma visão da história bem próxima àquela das filosofias do progresso burguesas. A crítica veemente que o autor direciona ao marxismo vulgar está fundada na recusa a uma visão determinista e "objetivista", alicerçada na ideia de um desenvolvimento e um progresso das forças produtivas que, inevitavelmente, culminariam no socialismo. Nessa visão da história,

O capitalismo foi declarado como seu próprio coveiro, simplesmente deixando que funcione até o fim. [...] Mesmo uma pitada de pessimismo seria preferível à fé no progresso automático [...], diante das terríveis possibilidades que estavam e estão implicadas no avanço capitalista (BLOCH, 2005, p. 197).

Nas linhas do texto de Ernst Bloch se desenha a recusa de uma concepção da história cujos conceitos de progresso e necessidade parecem necessariamente vincular-se. $\mathrm{Na}$ visão do autor, o marxismo vulgar havia aderido precisamente a uma visão da história não dialética, contemplativa e, desse modo, conformista. Na tematização da produção do novo na história como possibilidade, fazia-se necessário a crítica radical aquele

\footnotetext{
Otimismo banal e automático do progresso em si, que é apenas uma reprise do quietismo contemplativo. [Assim] o sujeito pode, então, cruzar os braços diante do Estado do futuro, que então se apresenta como consequência consumada dentro da chamada lógica férrea da história, do mesmo modo que havia juntado as mãos diante da resolução de Deus (BLOCH, 2005, p. 196).
}

Nessa perspectiva, a reabilitação da utopia como conceito chave para o pensamento político comparece no interior da valorização do fator subjetivo na história. Tal como escreve Gérard Raulet, a "reabilitação do fator subjetivo constitui tanto para Bloch como para nós uma prioridade face à petrificação mecanicista da dialética" (RAULET, 1976, p. 09). Ora, o que distinguiu o materialismo dialético do materialismo mecânico - lembremos a reflexão feita por

\begin{tabular}{|l|l|l|l|l|}
\hline Q Rovista Dialectus & Ano 10 & n. 21 & Janeiro - Abril 2021 & p. 116 - 135 \\
\hline
\end{tabular}


Bloch acerca do limite do materialismo naturalista de Feuerbach - foi precisamente a compreensão da atividade humana como o fundamento de todo o mundo histórico, do real como produção e autoprodução humana. Logo, na importante recusa do marxismo dominante, é necessário se ter claro que dialética e necessidade se excluem. Por isso, escreve Bloch que

\footnotetext{
Um enrijecido conceito de realidade por vezes penetrou até no marxismo, fazendo com que ele se tornasse esquemático. Não é suficiente falar de um processo dialético, e depois tratar a história como uma série de fatos fixos que sucedem um ao outro [...]. Aqui há o perigo de um estreitamento e de uma redução da realidade, um abandono da "força atuante e da semente" contidas nela - e isto não é mais marxismo (BLOCH, 2005, p. 196).
}

Desta feita, ao se opor ao marxismo vulgar e seu materialismo determinista, Bloch entende que não há transformação sem sujeito. É nessa direção que o filósofo reflete a necessidade de rastrear os fatores tanto objetivos quanto subjetivos das transformações históricas. Não por acaso, na segunda parte de O Princípio esperança, intitulada A consciência antecipadora, o filósofo alemão abre seu texto com uma pergunta: "Quem nos impulsiona" (BLOCH, 2005, p. 49).

Aqui retornamos à questão da utopia em Bloch. Devemos ter claro, como esclarece

Remo Bodei, "que de nenhum modo o conceito de utopia deve ser reduzido à sua dimensão política" (BODEI, 2005, p. XXIII). Num primeiro nível argumentativo - o qual não será aqui aprofundado -, a utopia corresponde à atividade humana orientada para o futuro, atividade essa que nega o presente marcado pela carência. A opus magna de Bloch, em grande medida, se constitui como uma grandiosa obra que busca atualizar o que já em $O$ Espírito da utopia vem denominado como "herança intacta". Essa herança diz respeito aos fenômenos utópicos da cultura do passado, em grande medida relegados ao esquecimento pela historiografia burguesa: a Utopia social de Morus, a arte expressionista, a teologia de Thomas Münzer, a utopia técnica em Nova Atlântida (de Bacon), etc. Assim, na visão de Ernst Bloch, para o marxismo crítico se apresentava a importância política de resgate das utopias, como um trabalho de memória histórica, e como "apropriação crítica do legado cultural” (BLOCH, 2005, 273). O autor vislumbra na função utópica presente na herança intacta um alimento para as lutas políticas do presente, cabendo ao marxismo revolucionário, pois, uma atualização, para o tempo presente, desta tradição do passado. Nessa perspectiva - como recusa de inúmeras leituras equivocadas do texto de Bloch, acusando-o de "subjetivismo" -, é necessário compreender que, na tessitura de suas preocupações filosóficas, de modo algum o autor afirma que 
As condições de emancipação se encontram na imaginação e não na história, mas [quer] mostrar que, se todas as lutas por libertação são condicionadas pelo estado das forças produtivas, elas são alimentadas por uma força utópica, pela esperança de uma ordem que constitui sua finalidade. Assim, é necessário reabilitar, no sentido do marxismo, uma antropologia da imaginação constituinte e da esperança militante. [...] Logo, encontrar na esperança e na imaginação de um mundo melhor a alavanca da revolução (PIRON-AUDARD, 1976, p. 109).

Quando afastado de suas atividades na Universidade de Leipzig na Alemanha Oriental, na década de 1950, um dos intelectuais fiéis ao regime acusava Bloch de revisionista do marxismo com as seguintes palavras:

\begin{abstract}
A filosofia blochiana está caracterizada particularmente por uma forte acentuação do fator subjetivo no processo de desenvolvimento. [...] Se encontra nela também uma particular predileção pelo pensamento do jovem Marx, enquanto o Marx maduro de $O$ Capital só aparece considerado como um economista que não tem nada a dizer aos filósofos. A acentuação do fator subjetivo leva ao desprezo às leis objetivas da natureza e da história (HAGER apud ZECCHI, 1978, p. 54-55).
\end{abstract}

No alerta quanto ao "perigo do economicismo e do oportunismo" (BLOCH, 2005, p. 206-207) que identificou no marxismo vulgar, Bloch realizou sua reflexão na perspectiva de contribuir para a rehabilitação da importância e do papel dos sujeitos nas transformações históricas. Foi, portanto, na direção de resgatar uma concepção materialista dialética da história que o filósofo recusou a teoria do reflexo para pensar o âmbito das superestruturas ideológicas. Nessa direção, em entrevista a Arno Münster em 1975, aos 90 anos, Ernst Bloch diz a seu interlocutor que "na relação entre infraestrutura e superestrutura, devemos falar também da influência da superestrutura sobre a infraestrutura, e não somente da influência devastadora da infraestrutura sobre a superestrutura, tal como o faz o marxismo vulgar" (BLOCH, 2016a, p. 202). Assim, ainda que as condições de última instância sejam sempre de ordem econômica, tal não significa que a superestrutura não atue sobre a base econômico-material. Dessa maneira, se falamos em processos dialéticos, temos que buscar relações recíprocas. É nesse sentido que Bloch fala de uma corrente quente da revolução capaz de atuar e alimentar as mudanças históricas:

\footnotetext{
A história das revoluções é, com efeito, muito antiga, ela não começa com Spartacus, mas muito tempo antes dele. $\mathrm{Na}$ época de Spartacus, já existia uma grande tradição do pensamento revolucionário [...]. Spartacus é impensável sem uma corrente quente, e é assim que o entendemos constantemente, que nós usamos seu nome diretamente [...], como testamento que entende que a revolução tem necessidade de uma corrente quente (BLOCH, 2016a, p. 199).
} 
Em sua vasta produção teórica, Ernst Bloch compreende o marxismo como uma "utopia concreta" e "filosofia do futuro". Tal viragem histórico-filosófica tornou-se possível ao compreender a práxis, a atividade humana, como o fundamento do real, capaz de superar a dualidade entre sujeito e objeto, conhecimento e ação, passado e futuro. No entender de Bloch, somente um materialismo que superou o pensamento contemplativo poderia compreender que o real - não sendo o objeto fixo, dado de uma vez por todas - é um processo aberto no interior de possibilidades.

O conhecimento acerca das possibilidades históricas necessita, com efeito, de uma corrente fria, que analisa as condições de possibilidade de qualquer transformação do real. Todavia, a corrente fria não pode prescindir da corrente quente da revolução - "a razão presente no irracional" (BLOCH, 2016a, p. 198) -, pois esta, além de alimento para as transformações históricas, mostra o alvo a ser buscado, indica o que não pode ser esquecido. Aqui ainda emerge a crítica de Bloch ao que chama de marxismo "falsificado", àquele que confundiu

\footnotetext{
Concretude com empirismo [...]. Que se rendia a um empirismo raso. Como constatamos, para os reformistas o movimento passou a ser tudo, o alvo, nada. E dessa forma o próprio caminho acabou. [...] O sectarismo pseudo-radical que incorre igualmente em empirismo, ou seja, priva o marxismo precisamente da riqueza e da vida de profundidade que esse empirismo não entende. [...] Quando Marx colocou a dialética com os pés no chão [...], definitivamente não anunciou o empirismo e o mecanicismo que lhe são análogos (mundo bipartido). [...] [Marx recusou a] subnutrição da fantasia revolucionária (BLOCH, 2006a, p. 176).
}

Insistir na importância de uma corrente quente do marxismo, capaz de contribuir no interior das lutas do povo, surge como recusa ao que Bloch chamou de "otimismo automático do progresso", que predominou no marxismo social-democrata. Tal concepção, na visão de Bloch, somente poderia conduzir ao conformismo, e, portanto, incapaz de contribuir a grandes transformações históricas. O pensamento capaz de conduzir de modo eficaz à crítica do presente somente pode se apresentar, conforme definição de Walter Benjamin, como ruptura com o continuum da história, ou seja, no rompimento com a barbárie que se maquia de novidade. Assim, o novo que pode emergir no real em processo, em um mundo inconcluso, somente pode surgir como ruptura, e não como continuidade no interior de uma pretensa "lógica férrea da história" (BLOCH, 2005, p. 196). Desta feita, conforme esclareceu Bloch em seu importante livro dedicado a Hegel, o pensamento que tornou o futuro passível de ciência representa um "materialismo que, pelo contrário, é interrupção" (BLOCH, 1963, p. 110) e, somente assim, caminho que abre espaço à produção do novo.

\section{Pensar ad pessimum: o futuro ainda em questão}


O conceito de progresso deve ser fundamentado na ideia de catástrofe. Que "as coisas continuem assim" - eis a catástrofe. Ela não consiste naquilo que está por acontecer em cada situação, e sim naquilo que é dado em cada situação. Assim Strindberg afirma (em Rumo a Damasco): o inferno não é aquilo que nos aguarda, e sim esta vida aqui.

(Walter Benjamin, Passagens [N 9a, 1])

No projeto de Ernst Bloch, refletir a atualidade da utopia como conceito filosófico fundamental se situava ante a necessidade de pensar o marxismo como teoria capaz de apontar as possibilidades no interior da realidade econômico-histórica. Tal é o pressuposto de um pensamento que refletiu o perigo representado por um otimismo absolutizado, bem como os riscos presentes num pessimismo absolutizado, tanto o de direita, quanto o de esquerda. É nessa medida que a ontologia do possível desenvolvida em $O$ princípio esperança surge como uma crítica radical do presente ao afirmar que

Enquanto a realidade não for completamente determinada, enquanto ela contiver possibilidades inconclusas em novas germinações e novos espaços de conformação, enquanto for assim, não poderá proceder da realidade meramente fática qualquer objeção absoluta contra a utopia (BLOCH, 2005, p. 195).

Tal projeto filosófico, todavia, acarretou e ainda acarreta inúmeras interpretações equivocadas. Como escreve o escritor italiano Remo Bodei, sobre a produção filosófica de Ernst Bloch "existem sucessivamente projetadas imagens inadequadas e de sentido oposto, que o apresentam como um inconsciente fautor de funestos e inaplicáveis modelos de perfeição" (BODEI, 2005, p. XIV). A tematização do futuro, ao mesmo tempo em que recusa o pessimismo distópico, se afasta, com efeito, do otimismo absolutizado e da consequente ideia de futuro que marcou a modernidade, bem como se afasta da otimista "fé" em um progresso histórico que caminha em direção ao melhor. Logo, é um equívoco interpretar a utopia em Bloch na perspectiva de uma visão rasa e otimista do futuro.

Mesmo um dos mais importantes intérpretes de Ernst Bloch, ao refletir corretamente que na obra do filósofo existe um projeto filosófico que busca fundamentar a recusa do pessimismo, recai no erro de apontar no pensador marxista um otimismo quase cego. Assim, acerca da ontologia do ainda-não-ser e do conceito do possível, acreditamos haver um equívoco na leitura de Arno Münster ao entender que, na filosofia de Bloch,

O conceito de 'futuro' é definido exclusivamente numa conotação positiva, isenta de catástrofe. Isso torna a sua visão messiânica do mundo, sobretudo a visão da esperança messiânica do judaísmo, problemática. Como manter essa visão frente ao peso e à força da negatividade na história moderna e contemporânea, frente à Auschwitz? (MÜNSTER, 1993, p. 100) 
Conforme já tratamos, é justamente por caminhar na direção contrária a de um otimismo cego que o pensador alemão aqui tratado surge como um crítico não somente das filosofias burguesas da história e de sua visão do progresso, mas também ao marxismo que adotou, ele próprio, a concepção de um curso da história que caminha inevitável em direção a um futuro melhor. Essa "fé" positivista no progresso somente pode conduzir, conforme o autor elucida em $O$ Princípio esperança, à "ilusão de um êxito e um avanço que nada consegue atrapalhar" (BLOCH, 2005, p. 250).

Em sua ontologia do ainda-não-ser, o conceito de possibilidade, enquanto capacidade objetiva, constitui o poder-tornar-se diferente do real exterior aos homens. Todavia, as condições de possibilidade objetivas devem ir de encontro com o poder-fazer-diferente da intervenção humana, de tal modo que "a categoria objetal possibilidade revela-se também, predominantemente, como aquilo que ela não pode ser por si mesma, mas sim pela intervenção promotora dos seres humanos naquilo que ainda pode ser mudado" (BLOCH, 2005, p. 230).

Tendo vivido a "era das catástrofes" - conforme definição do historiador Eric Hobsbawm - que representou o capitalismo da era dos campos de concentração e de guerras com poder de destruição tão radicais, Ernst Bloch tinha a clareza de que o conceito do possível (e o futuro) tem uma abertura, igualmente, na direção contrária àquela da realização da liberdade e emancipação humana na história. Se não fosse assim, o conceito do possível - e de utopia, futuro e novidade - perderia sua dimensão de crítica de uma sociedade que produz a tudo e a todos como mercadoria. É nessa medida que a categoria da possibilidade revela-se

\begin{abstract}
Igualmente como possível conceito de desgraça, e isto justamente devido ao poderfazer-diferente, mas também devido ao poder-tornar-diferente contido nele, que abre espaço, na mesma medida, para uma guinada para o pior [...]. Essa precariedade, como constitutivo negativo da possibilidade objetal, abrange desde o acidente que pode ocorrer até a irrupção do inferno fascista, que residia e ainda reside como possibilidade no último estágio do capitalismo. O caráter funesto do possível concorre assim com o caráter salvífico apontado, com o caráter esperançoso do possível, que, como tal, igualmente reside na mutabilidade de uma situação (BLOCH, 2005, p. 230).
\end{abstract}

Em outros termos, os conceitos de possibilidade e de utopia somente podem se articular no interior de uma teoria social crítica porque surgem como categorias que recusam veementemente a certeza conformista de que o futuro será melhor. Desta feita, o otimismo automático, associado a um ideal de progresso inevitável, "não é menos venenoso do que o pessimismo absolutizado" (BLOCH, 2005, p. 197). Por tal razão podemos refletir, junto de 
Ernst Bloch, que um pessimismo controlado, não absolutizado, pode ser tomado numa perspectiva que pode ter um viés crítico ao analisarmos o capitalismo de nosso tempo.

É nessa perspectiva que, em $O$ Princípio esperança, escreve o pensador alemão que "pensar ad pessimum é, para toda análise que não o absolutiza, um companheiro de viagem melhor que a ingenuidade barata, e ele constitui a frieza crítica justamente no marxismo" (BLOCH, 2005, p. 197). Nessa direção, Bloch opõe o "otimismo militante" - que intervém no interior das possibilidades - ao pessimismo resignado, pois este atua como se fosse "o fim das possibilidades. A possibilidade [é ainda] a categoria mais estrangeira desse imenso laboratório que é o mundo, um laboratório pleno de trabalho do possibile salutis" (BLOCH, 2016b, p. 171). O que a ontologia blochiana do ainda-não-ser tenta postular é que o pessimismo absolutizado é, em geral, pouco científico em seu olhar sobre o real como história.

Nas linhas de $O$ Princípio esperança, texto escrito no exílio de Bloch nos Estados Unidos durante a Segunda Guerra mundial, Bloch critica o pessimismo absolutizado que, já no século XIX, marcou a filosofia de pensadores como Nietzsche e Schopenhauer. A crítica se direciona a tais pensadores no preciso aspecto em que se caracterizam como filosofias niilistas e conformistas que acabaram por ontologizar realidades transitórias, tomadas como o inexorável na vida dos homens. Na produção teórica de Bloch se desenha - na linha de uma ontologia do possível que conclui que "o mundo, assim como existe, não é verdadeiro" (BLOCH apud LÖWY, 1998, p. 297) - a recusa de perspectivas filosóficas que fazem do pessimismo, do medo e "da angústia o puro e simples e indiferenciado ser-assim em tudo, o 'estado existencial fundamental', [...] [absolutizando tão somente] o estado fundamental de uma sociedade em declínio" (BLOCH, 2005, p. 111). Em outros termos, se entende como necessário deslegitimar qualquer justificação ou legitimação filosófica do mundo existente, tratando-o como um fato consumado contra o qual nada se pode fazer.

Como sabemos, o filósofo aqui em questão abraçou em seu pensamento múltiplas influências. Para além de Hegel e Marx, sua herança mais próxima e mais radical, ele passa por Aristóteles, pelos árabes medievais como Avicena e Averróis, pelo Renascimento de Morus e Giordano Bruno, dentre outros. Suas fontes filosóficas são tão amplas que o pensador assumidamente marxista retira elementos que julga relevantes mesmo de autores por ele tão criticados. Assim, acerca do que chama pensar ad pessimum, em entrevista a José Marchand, no ano de 1974, o enciclopédico Ernst Bloch avalia que "a esperança não pode ser pensada sem Schopenhauer" (BLOCH, 2016b, p. 173-174). 
É necessário mais uma vez enfatizar que a tentativa de estabelecer a atualidade do conceito de utopia no contexto do século XX de modo algum deve ser lido como externo ao debate marxista. E, nessa direção, compreende que na "riqueza do marxismo [...] [faz-se fundamental uma] apropriação crítica do legado cultural" (BLOCH, 2005, p. 273), fazendo um "uso diabólico" da herança intacta presente nas utopias pregressas. Esse projeto seria, em sua visão, da maior importância prática: como alimento das lutas do presente, mas também para não permitir que a história da corrente quente seja esquecida, ou mesmo contada pelos vencedores. O princípio esperança presente nessas obras da cultura, ressalta sempre o filósofo, deve ser lido em seu potencial crítico, vinculado às possibilidades no interior do real em processo,

\footnotetext{
Pois do contrário ela não seria mais que uma frase ou uma forma miserável de confiança. E isso é justamente o que a esperança está longe de ser. A esperança não é sinônimo de confiança, mas um chamado a nós, humanos, que somos a vanguarda do processo do mundo e que temos a tarefa de humanizá-lo ou, como diz Marx, de se abrir à "humanização da natureza e à humanização do homem". [...] Isso significa acelerar o nascer do sol, ajustar os ponteiros do processo do mundo, na possibilidade sempre presente, na categoria "possibilitas" e em outra categoria, a "potentia" do homem, quer dizer, a potência de transformar o mundo, no sentido que lhe dá Marx, mas também num sentido que o amplia: a força de fazer aparecer o rosto humano que dorme e cuja existência é tão difícil (BLOCH, 2016b, p. 173-174).
}

No contexto do capitalismo contemporâneo, a atualidade do pensamento de Ernst Bloch se localiza, certamente, na ênfase dada acerca dos riscos representados por um otimismo absolutizado, àquele que predominou em parcela do marxismo dominante em sua época. É nessa direção que o pensar ad pessimum, apropriadamente tomado, pode ter um viés crítico se refletido de um modo distinto do pessimismo resignado e absolutizado. Esse viés crítico somente pode ganhar existência, com efeito, se o pessimismo for tomado pelo otimismo militante: aquele que atua no interior do possível, estando ciente dos riscos representados pelo estágio de desenvolvimento do capitalismo como o século XX conheceu.

O pensar ad pessimum se coloca no texto de Ernst Bloch tal qual, de certo modo, se dá na obra de Walter Benjamin. De fato, na crítica de nosso tempo, trata-se de uma produção teórica que deve ser afastada de um marxismo do tipo social democrata, e aproximado da riqueza teórica de uma filosofia como a de Walter Benjamin. Nesse sentido, refletir acerca das possibilidades históricas requer, igualmente, a consciência dos riscos que tem surgido na realidade econômico-histórica. É nessa medida que, na aposta de uma humanização da natureza, naturalização do humano, junto de Walter Benjamin, seu amigo de juventude, Bloch 
bem poderia ter escrito em $O$ Princípio esperança: "antes que a centelha chegue à dinamite, é preciso que o pavio que queima seja cortado" (BENJAMIN, p. 45-46). Eis o ainda atual paradigma político enunciado na $11^{\mathrm{a}}$ Tese de Marx contra Feuerbach, a mais importante para Ernst Bloch.

\section{Referências}

ADORNO, Theodor Wiesengrund; HORKHEIMER, Max. A Dialética do Esclarecimento: fragmentos filosóficos. Trad. Guido de Almeida. Rio de Janeiro: Zahar, 1985.

ANDREUCCI, Franco. A difusão e a vulgarização do marxismo. In: HOBSBAWM, Eric (Org). História do marxismo: o marxismo na época da Segunda Internacional. Vol. II. Trad. Leandro Konder e Carlos Nelson Coutinho. Rio de Janeiro: Paz e terra, 1982.

BENJAMIN, Walter. Sobre o conceito de história. In: Magia e Técnica. Arte e Política. Trad. Sérgio Paulo Rouanet. 7. ed. São Paulo: Brasiliense, 1994.

BENJAMIN, Walter. Aviso de Incêndio: Rua de mão única. In: Obras escolhidas. Vol. II. Trad. de Rubens Rodrigues e José Carlos Martins. Brasiliense: São Paulo, 1987.

. Passagens. Traduções de Irene Aron e Cleonice P. B. Mourão e organizado por Willi Bolle e Olgária Matos. Belo Horizonte: Editora da UFMG; São Paulo: Imprensa Oficial do Estado de São Paulo, 2007.

BLOCH, Ernst. Du rêve à l'utopie: Entretiens philosophiques. Textos escolhidos e prefaciados por Arno Münster. Paris: Hermann, 2016a.

El pensamiento de Hegel. Trad. Wenceslao Roces. Mexico; Buenos Aires: Fondo de Cultura Economica, 1963.

Il Principio Speranza. Trad. Enrico d'angelis e Tomaso Cavallo. Pref. di Remo Bodei. Milano: Garzanti, 2005.

L'esprit de l'utopie [1918-1023]. Trad. Anne Marie Lang e Catherine Tiron-Audard. Paris: Gallimard, 1977.

O Princípio Esperança [1954-1959]. Vol. I. Nélio Schneider. Rio de Janeiro: EdUERJ; Contraponto, 2005.

O Princípio Esperança [1954-1959]. Vol. II. Werner Fuchs. Rio de Janeiro: EdUERJ; Contraponto, 2006a.

O Princípio Esperança [1954-1959]. Vol. III. Nélio Schneider. Rio de Janeiro: EdUERJ; Contraponto, 2006b. 
Rêve diurne, station debout et utopie concrète: Ernst Bloch en dialogue (Entrevistas com José Marchand em 1974. Trad. fr. de Arno Münster). Editions Lignes: Paris, $2016 b$.

BODEI, Remo; PIZZOLATO, Luigi Franco. A política e a felicidade. Trad. Antonio Agonese. São Paulo: EDUSC, 2000.

FURTER, Pierre. A dialética da esperança: uma interpretação do pensamento utópico de Ernst Bloch. Rio de Janeiro: Paz e terra, 1974.

HABERMAS, Jürgen. Ernst Bloch: um Schelling marxista. In: Habermas. Trad. e org. Bárbara Freitag e Sérgio Paulo Rouanet. Editora Ática: São Paulo, 1993.

KORSCH, Karl. Marxismo e Filosofia [1923]. Trad. Antonio Sousa Ribeiro. Porto: Afrontamento, 1966.

KOSELLECK, Reinhart. Crítica e crise: uma contribuição à patogênese do mundo burguês. Trad. Luciana Villas-Boas Castelo Branco. Rio de janeiro: contraponto, 1999.

. Futuro Passado: contribuição à semântica dos tempos históricos. Trad.

Wilma Patrícia Maas e Carlos Almeida Pereira. Rio de Janeiro: Contraponto, 2006.

LÖWY, Michael. A evolução política de Lukács (1909-1929). Trad. Heloísa E. Mello e Agostinho F. Martins. São Paulo: Cortez, 1998.

MACIEL, Marta M. A. Ernst Bloch e Walter Benjamin: Reflexões acerca das afinidades eletivas. In: Problemata (Revista Internacional de Filosofia). Edição especial: Marxismo e teoria crítica. v. 10, n. 4, 2019, p. 339-359.

MACIEL, Marta M. A.; VIEIRA, A. R. A tematização do futuro no pensamento de Ernst Bloch ou a crítica às filosofias do passado. In: SOUZA, Ricardo Timm e RODRIGUES, U. M. (Orgs.). Ernst Bloch: atualidade das utopias concretas. Vol I. Porto Alegre: Editora Fi, 2016, p. 178-203.

MÜNSTER, Arno. Utopia, messianismo e apocalipse nas primeiras obras de Ernst Bloch. Trad. Flávio Breno Siebeneichler. São Paulo: UNESP Editora, 1997.

PIRON-AUDARD, Catherine. Anthropologie marxiste et psychanalyse selon Ernst Bloch. In: RAULET, Gérard (org.). Utopie-marxisme selon Ernst Bloch: un système de l'inconstructible. Payot: Paris, 1976.

RUSSELL, Jacoby. O fim da utopia. Política e cultura na época da apatia. Trad. de Clóvis Marques. Rio de janeiro: Record, 2001.

RAULET, Gérard (org.). Utopie-marxisme selon Ernst Bloch: un système de l'inconstructible. Payot: Paris, 1976.

STEINBERG, Hans-Josef. O partido e a formação da ortodoxia marxista. In: HOBSBAWM, Eric (Org). História do marxismo: o marxismo na época da Segunda

\begin{tabular}{|l|l|l|l|l|}
\hline Q Rovista Dialectus & Ano 10 & n. 21 & Janeiro - Abril 2021 & p. 116-135 \\
\hline
\end{tabular}


Internacional. Vol. II. Trad. Leandro Konder e Carlos Nelson Coutinho. Rio de Janeiro: Paz e terra, 1982.

VIEIRA, Antonio Rufino. Marxismo e libertação: estudos sobre Ernst Bloch e Enrique Dussel. São Leopoldo: Nova Harmonia, 2010.

ZECCHI, Stefano. Ernest Bloch: Utopia y Esperanza en el Comunismo [1974]. Trad. Enric Pérez Nadal. Barcelona: Península, 1978. 